Article

\title{
Application of Carbon-Microsphere-Modified Electrodes for Electrochemistry of Hemoglobin and Electrocatalytic Sensing of Trichloroacetic Acid
}

\author{
Wen-Cheng Wang, Li-Jun Yan, Fan Shi, Xue-Liang Niu, Guo-Lei Huang, Cai-Juan Zheng * \\ and Wei Sun \\ Received: 29 October 2015; Accepted: 17 December 2015; Published: 23 December 2015 \\ Academic Editors: Yu Lei, Ashutosh Tiwari and Hongyun Liu \\ Key Laboratory of Tropical Medicinal Plant Chemistry of Ministry of Education, \\ College of Chemistry and Chemical Engineering, Hainan Normal University, Haikou 571158, China; \\ Sdwangwencheng@126.com (W.-C.W.); 18289751071@163.com (L.-J.Y.); shifan0802@126.com (F.S.); \\ xueliangniu@163.com (X.-L.N.); huangguolei1982@163.com (G.-L.H.); sunwei@qust.edu.cn (W.S.) \\ * Correspondence: caijuan2002@163.com; Tel./Fax: +86-898-3138-1637
}

\begin{abstract}
By using the hydrothermal method, carbon microspheres (CMS) were fabricated and used for electrode modification. The characteristics of CMS were investigated using various techniques. The biocompatible sensing platform was built by immobilizing hemoglobin $(\mathrm{Hb})$ on the micrometer-sized CMS-modified electrode with a layer of chitosan membrane. On the cyclic voltammogram, a couple of quasi-reversible cathodic and anodic peaks appeared, showing that direct electrochemistry of $\mathrm{Hb}$ with the working electrode was achieved. The catalytic reduction peak currents of the bioelectrode to trichloroacetic acid was established in the linear range of 2.0 70.0 mmol. $\mathrm{L}^{-1}$ accompanied by a detection limit of $0.30 \mathrm{mmol} \cdot \mathrm{L}^{-1}(3 \sigma)$. The modified electrode displayed favorable sensitivity, good reproducibility and stability, which suggests that CMS is promising for fabricating third-generation bioelectrochemical sensors.
\end{abstract}

Keywords: hemoglobin; carbon microsphere; direct electrochemistry; trichloroacetic acid

\section{Introduction}

Recently, the electrochemical behavior of proteins has roused great interest, and the results can be applied to the study of electron transfer mechanisms in biosystems and the construction of third-generation electrochemical biosensors or biofuel cells [1,2]. However, the electroactive centers are often buried in the polypeptide chains of redox proteins, which make electron transfer of proteins in a conventional biosensor more difficult [3]. Therefore, various protein-based biosensors have been fabricated for the realization of electrochemical behavior with the usage of multifarious modifiers such as polymers, surfactants and nanosized materials [4,5]. The existence of modifiers can preserve the original structure of redox proteins and their enzymatic activity, which offer a suitable microenvironment for electron transfer between electrode and proteins.

Nanomaterials with multifarious morphologies and unique properties such as excellent biocompatibility and large surface area have been applied to the electrochemistry of protein [6]. Among them, carbon nanomaterials are commonly used due to their excellent electrical conductivity. Various carbon materials have been applied to the investigation of electrochemical behavior of proteins, such as mesoporous carbon [7], carbon nanotubes (CNT) [8], and graphene (GR) $[9,10]$. Carbon microspheres (CMS) are a kind of carbon material that has been widely investigated. Shin et al. proposed a hydrothermal technique for the fabrication of colloidal spheres from aqueous cyclodextrin solution [11]. Sun et al. prepared core-shell structures of colloidal carbon spheres with 
the loading of different nobel-metal nanoparticles [12]. Chen et al. synthesized monodispersed carbon spheres from glucose for the supercapacitor [13]. Jin et al. proposed a direct hydrocarbon pyrolysis technique for the large-scale synthesis of carbon spheres [14]. The synthesized carbon spheres can be used for the loading of other nanomaterials and applied in different fields such as magnetism, catalysis and biosensor [15-17]. However, few reports about the application of CMS in the field of protein electrochemistry have been found.

In the present study, CMS was synthesized from glucose using a hydrothermal method and was further applied to the protein electrochemistry. CMS-hemoglobin $(\mathrm{Hb})$ composite was prepared and cast on the ionic liquid modified carbon paste electrode (CILE) surface. Then, CTS were cast for the immobilization of the composite on the electrode surface. The fabrication procedure of this $\mathrm{Hb}$ modified electrode is shown in Scheme 1. CILE has exhibited many advantages, such as wide electrochemical windows, high conductivity, good antifouling capability and inherent electrocatalytic ability, which is reported in electroanalysis and electrochemical sensors $[18,19]$. CTS is an abundant natural cationic biopolymer that is composed of structural repeating units of $\mathrm{N}$-acetyl-glucosamine and glucosamine, which offers a biocompatible microenvironment for the immobilized redox proteins. Therefore, CTS-modified electrodes have been commonly used in electrochemical biosensors [20]. The synthesized CMS were checked using different techniques and exhibited large surface area with porous structure. On CTS/CMS-Hb/CILE the direct electrochemistry of $\mathrm{Hb}$ was carried out and the electrocatalysis of trichloroacetic acid (TCA) was achieved, demonstrating the potential applications of this electrochemical sensor.

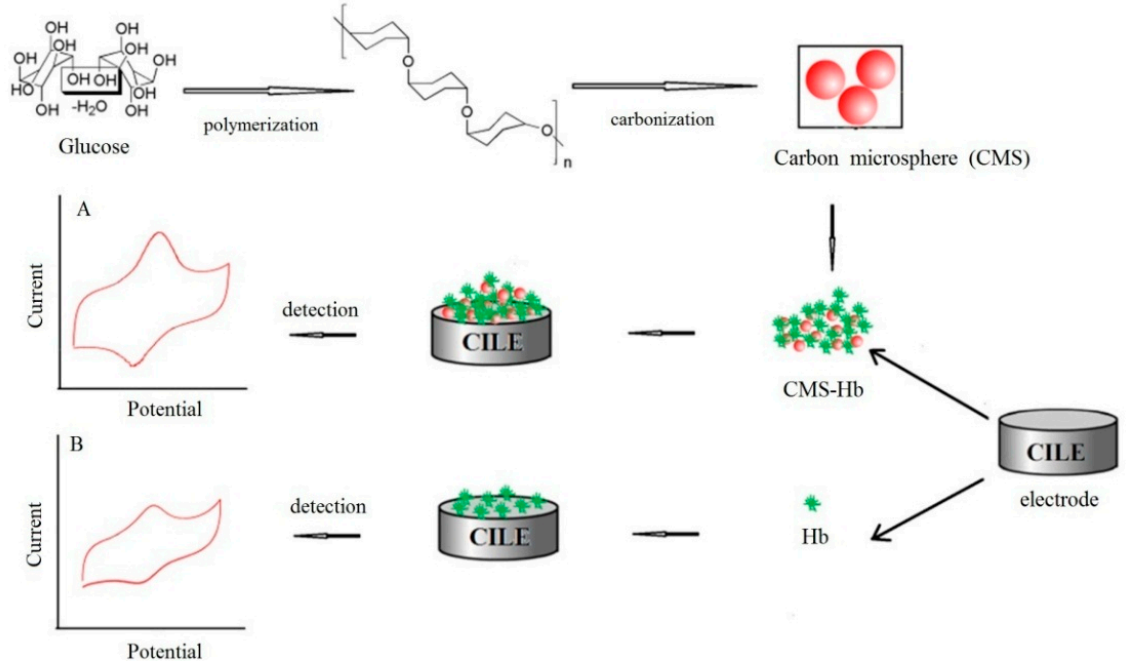

Scheme 1. The fabrication process of this $\mathrm{Hb}$ modified electrode.

\section{Experimental}

\subsection{Reagents}

Glucose (Beijing Chem. Reagent Factory, Beijing, China), Hb (Sinopharm. Chem. Reagent, Shanghai, China), 1-butylpyridinium hexafluorophosphate $\left(\mathrm{BPPF}_{6}>99 \%\right.$, Lanzhou Greenchem. CAS., Lanzhou, China), chitosan (CTS, Dalian Xindie Ltd., Dalian, China) graphite powder $(30 \mu \mathrm{m}$, Shanghai Colloid Chem., Shanghai, China) and TCA (Tianjin Kemiou Chem. Ltd., Tianjin, China).The experiments were conducted in $0.1 \mathrm{~mol} \cdot \mathrm{L}^{-1}$ phosphate buffer saline (PBS) at room temperature $\left(25 \pm 1^{\circ} \mathrm{C}\right)$, which was bubbled with pure $\mathrm{N}_{2}$ for half hour before experiments to deoxygenate and keep under $\mathrm{N}_{2}$ atmosphere during the electrochemical measurements. Ultrapure water and other chemicals (analytical reagent grade) were used in the experiments. 


\subsection{Apparatus}

CHI 660D workstation (Shanghai CH Instrument, Shanghai, China); Nicolet 6700 FT-IR spectrophotometer (Thermo Fisher Scientific Inc., Waltham, Massachusetts, USA); TU-1901 double beam UV-Visible spectrophotometer (Beijing General Instrument Ltd. Co., Beijing, China); Renishaw InVia Raman microspectrometer using $532 \mathrm{~nm}$ lasers (Renishaw Plc., London, UK); JSM-7100F scanning electron microscope (Japan Electron Co., Tokyo, Japan); FEI Tecnai G2 F20 microscope (FEI, Hillsborough, Oregon, USA) with a field-emission gun operating at $200 \mathrm{kV}$; D8 advance X-ray diffractometer (Germany Bruker Co., Karlsruhe, Germany). A three-electrode system was used with a modified electrode (the working electrode), platinum wire (the counter electrode) and saturated calomel electrode (SCE, the reference electrode).

\subsection{Synthesis of CMS}

CMS was fabricated on the basis of the previous report [12]. In general, $8.0 \mathrm{~g}$ of glucose was added to $40 \mathrm{~mL}$ water with ultrasonic agitation for $2 \mathrm{~min}$ to get a colorless solution, which was positioned in teflon-sealed autoclave and kept for $4 \mathrm{~h}$ in $180{ }^{\circ} \mathrm{C}$. The brown or black product was segregated by centrifugal separation, cleaned by 3 cycles of centrifugal separation/washing/re-dispersion in water and alcohol, and dehydrated at $80{ }^{\circ} \mathrm{C}$ for over $4 \mathrm{~h}$ to get black powder. A $1.0 \mathrm{mg} \cdot \mathrm{mL}^{-1} \mathrm{CMS}$ liquor was produced by redispersing CMS into the water with ultrasonic agitation for $3 \mathrm{~h}$ to get a homogeneous suspension solution.

\subsection{Electrode Fabrication}

CILE was manufactured as described previously [21]. In brief, graphite powder were mixed thoroughly with ionic liquid $\mathrm{BPPF}_{6}$ at $3 / 1(\mathrm{w} / \mathrm{w})$ in a mortar, then the paste was inserted into a glass tube $\left(\phi=4.0 \times 10^{-3} \mathrm{~m}\right)$. Prior to use, CILE was smoothed to get a mirror-like surface.

The step of fabricating the modified electrode was as follows. A $6.0 \mu \mathrm{L}$ of $0.5 \mathrm{mg} \cdot \mathrm{mL}^{-1}$ CMS and $15.0 \mathrm{mg} \cdot \mathrm{mL}^{-1} \mathrm{Hb}$ mixture solution was directly cast on the CILE surface with a $10.0 \mu \mathrm{L}$ microsyringe. Then, the working electrode (CTS/CMS-Hb/CILE) was fabricated by spreading $5.0 \mu \mathrm{L}$ of $1.0 \mathrm{mg} \cdot \mathrm{mL}^{-1}$ chitosan (in $1.0 \% \mathrm{HOAC}$ ) solution evenly onto the CMS-Hb/CILE surface. A uniform film on the modified electrode was formed by covering a beaker to alleviate the evaporated solution. The preparation processes of CTS/Hb/CILE, CTS/CMS/CILE, CTS/CILE etc., were parallel to that of CTS/CMS-Hb/CILE.

\section{Results and Discussion}

\subsection{Morphological and Structural Characterization}

SEM images of CMS with different magnification are shown in Figure 1A,B. It can be seen that the synthesized CMS had an average diameter of $600 \mathrm{~nm}$, which was in good agreement with the reference [12]. TEM images of CMS at different magnitude were shown as Figure 1C,D, which exhibited that the solid structure of the surface had many nanosized pores. These pores on the surface of CMS could be attributed to the release of unreacted organic compounds such as oligosaccharides that been washed by water and alcohol. The existence of pores could offer large surface area and more reactive species for aiding in penetration and adsorption. Based on the reference [12], this synthesis process of CMS is a completely environmental-friendly procedure without the employment of any poisonous reagents, surfactants or organic reagent. Therefore the as-prepared CMS are nontoxic, with potential applications in biosensors or bioelectrochemistry.

The graphitization degrees of CMS were further checked by XRD and Raman spectroscopy. As shown in Figure 1E, two peaks at $22.5^{\circ}$ and $42.8^{\circ}$ appeared on XRD, which could be specified as the typical graphitic (002) and (100) planes. The broadening of these two peaks suggests that the degree of graphitization was low and the amorphous carbon was possibly subsistent [14]. Figure 1F shows 
the Raman spectrum of CMS, which had one significant peak at $1574.0 \mathrm{~cm}^{-1}$. This peak corresponds to the G-band that is attributed to the ordered graphite structure [22].

The functional groups on CMS were further characterized by an FT-IR spectrum with the result shown in Figure 1G. The $\mathrm{O}-\mathrm{H}$ bond stretching vibration led to the strong characteristic peak at $3434.7 \mathrm{~cm}^{-1}$. The $\mathrm{C}-\mathrm{H}$ bond stretching vibration led to the weak peaks at $3172.4 \mathrm{~cm}^{-1}$ and $2927.5 \mathrm{~cm}^{-1}$. The absorption bands at $1398.2 \mathrm{~cm}^{-1}$ corresponded to $C-C$ stretching vibration and that of $1625.7 \mathrm{~cm}^{-1}$ was the carboxyl groups $(\mathrm{C}=\mathrm{O})$ stretching vibration [13]. Therefore, on the surface of CMS, many functional groups were present, which resulted in the hydrophilicity and stability of CMS in aqueous solution. As shown in Figure 1H, the CMS solution could remain stable for 2 days without congregation, indicating that CMS was stable in water and could be used for bioapplications.
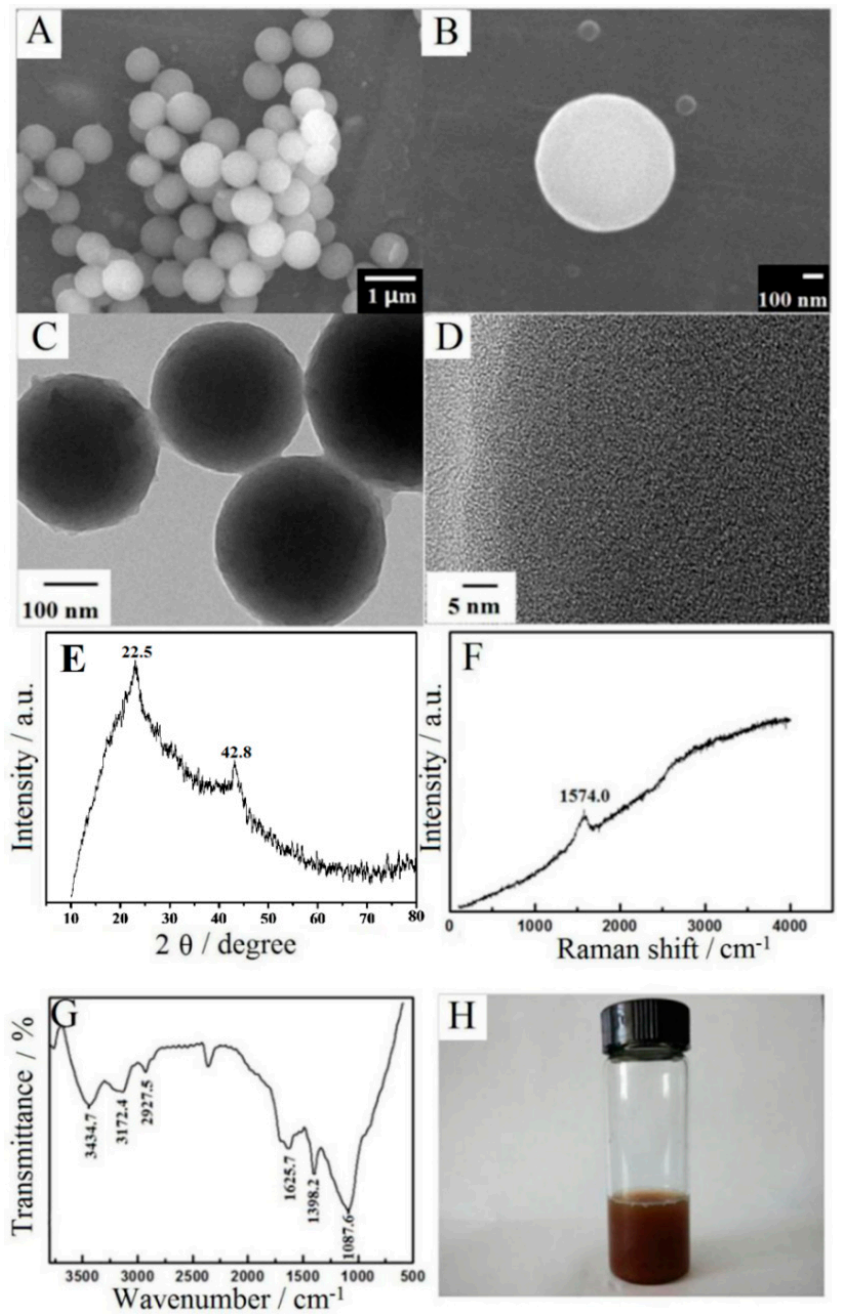

Figure 1. (A,B) SEM; (C,D) HRTEM; (E) XRD; (F) Raman spectrum; (G) FT-IR spectrum of CMS; (H) Photo of $1.0 \mathrm{mg} \cdot \mathrm{mL}^{-1} \mathrm{CMS}$ solution that kept for 2 days.

\subsection{Spectroscopic Results}

FT-IR spectroscopy was employed to examine the integrity of the structure and structural changes of the proteins [23]. Detailed data of the polypeptide chain could be determined from the shapes of amide I and II [24]. The amide I $\left(1650.8 \mathrm{~cm}^{-1}\right)$ and II band $\left(1542.8 \mathrm{~cm}^{-1}\right)$ of $\mathrm{Hb}$ after being mixed with CMS is shown in Figure $2 \mathrm{Ab}$, which had less difference compared with amide I $\left(1647.0 \mathrm{~cm}^{-1}\right)$ and II $\left(1533.2 \mathrm{~cm}^{-1}\right)$ bands of the native $\mathrm{Hb}$ (Figure 2Aa). The results indicated that the original structure of $\mathrm{Hb}$ after being mixed with CMS was unchanged. UV-Vis adsorption 
spectroscopy is another useful tool to monitor the conformation change of heme proteins [25]. The $\mathrm{Hb}$ molecules had a characteristic band $(406.0 \mathrm{~nm}$ ) in $\mathrm{pH} 3.0 \mathrm{PBS}$ (Figure 2Ba), which was the same as that of $\mathrm{CMS}-\mathrm{Hb}$ (Figure $2 \mathrm{Bb}$ ), meaning $\mathrm{Hb}$ molecules retained their original conformation in the $\mathrm{CMS}-\mathrm{Hb}$ solution. All the spectroscopic research indicated that the biocompatibility of $\mathrm{CMS}$ and $\mathrm{Hb}$ kept the fundamental active conformation of the original structure after being mixed with CMS.
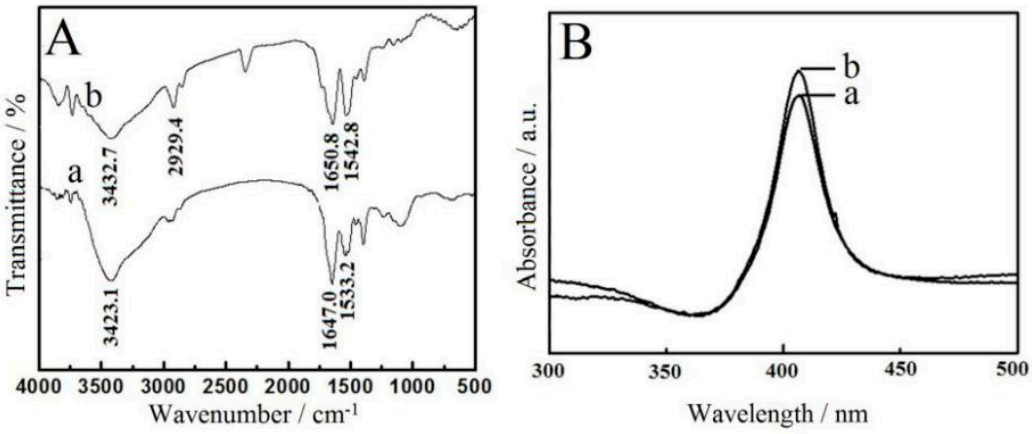

Figure 2. (A) FT-IR spectra of $\mathrm{Hb}$ (a) and CMS- $\mathrm{Hb}$ (b); (B) UV-Vis spectra of $\mathrm{Hb}$ (a) and CMS- $\mathrm{Hb}(\mathbf{b})$.

\subsection{Electrochemical Characterization}

Electrochemical behaviors were verified by cyclic voltammetry in the $0.1 \mathrm{~mol} \cdot \mathrm{L}^{-1} \mathrm{KCl}$ and $10.0 \mathrm{mmol} \cdot \mathrm{L}^{-1}\left[\mathrm{Fe}(\mathrm{CN})_{6}\right]^{3-/ 4-}$ mixture solution and the results are shown in Figure $3 \mathrm{~A}, \mathrm{~B}$. On CILE (Figure 3Aa) a couple of symmetric redox peaks was shown and it was the representative response of CILE. The electrochemical response of CTS/CILE (Figure 3Ab) was weaker than that of CILE, which was attributed to the existence of unconductive CTS on the surface of electrode impeding the electron transfer. The smallest redox peak currents appeared on CTS/Hb/CILE (Figure 3Bc), proving that the existence of $\mathrm{Hb}$ molecules on the electrode surface further impeded the electron transfer. However, on CTS/CMS-Hb/CILE (Figure 3Bd) the redox peak currents increased with the highest value, which was ascribed to the existence of CMS that promoted the electron transfer rate of $\left[\mathrm{Fe}(\mathrm{CN})_{6}\right]^{3-/ 4-}$ with increased responses.

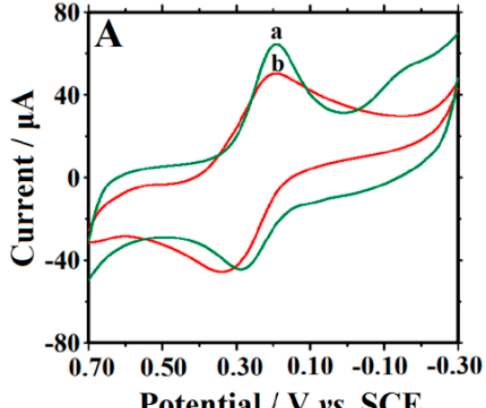

Potential / V vs. SCE
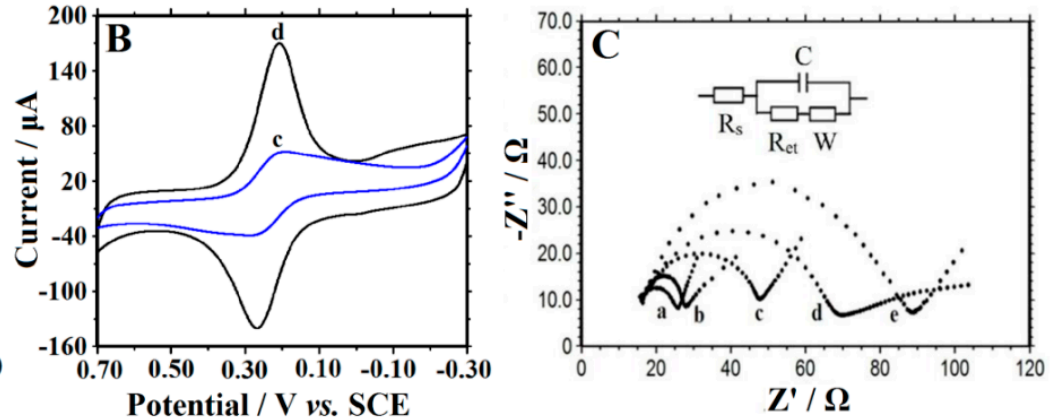

Figure 3. CV of (A) CILE (a), CTS/CILE (b); (B) CTS/Hb/CILE (c), CTS/CMS-Hb/CILE (d) in a $10.0 \mathrm{mmol} \cdot \mathrm{L}^{-1}\left[\mathrm{Fe}(\mathrm{CN})_{6}\right]^{3-/ 4-}$ and $0.1 \mathrm{~mol} \cdot \mathrm{L}^{-1} \mathrm{KCl}$ solution, scan rate:0.1 $\mathrm{V} \cdot \mathrm{s}^{-1}$; (C) EIS of (a) CTS/CMS/CILE; (b) CTS/CMS-Hb/CILE; (c) CILE; (d) CTS/CILE and (e) CTS/Hb/CILE with the frequencies ranging from $10^{5}$ to $10^{-1} \mathrm{~Hz}$. (Inset is the Randles circuit model in the cell).

Figure 3C shows the electrochemical impedance spectroscopy (EIS) of different electrodes, which was employed to investigate the interfacial information [26]. The electron transfer resistance $\left(R_{e t}\right)$ value of CILE was found to be $37.97 \Omega$ (curve c) and that of CTS/CILE increased to $54.75 \Omega$ (curve d), proving that the interfacial resistance was increased with the existence of unconductive CTS film. On CTS/Hb/CILE (curve e) the $R_{e t}$ was $82.83 \Omega$, which could be ascribed to the existence of Hb further 
increasing the interfacial resistance. While on CTS/CMS/CILE (curve a) and CTS/CMS-Hb/CILE (curve b) the $R_{\text {et }}$ decreased to $10.76 \Omega$ and $15.25 \Omega$, respectively, showing that the existence of CMS decreased the resistance. CMS is a carbon material with good conductivity that can quicken the electron transfer.

\subsection{Direct Electrochemistry of $\mathrm{Hb}$}

Figure 4 showed the electrochemical behaviors of different modified electrodes in PBS (pH 3.0). No redox peaks were found on CTS/CILE (curve a) and CTS/CMS/CILE (curve b). With a layer of IL present on the surface, CILE exhibits good conductivity and a biocompatible surface [9], and a couple of asymmetric redox peaks were found on CTS/Hb/CILE (curve c), showing that direct electron transfer between $\mathrm{Hb}$ and CILE was realized. On CTS/CMS-Hb/CILE the redox peaks increased greatly (curve d), which remained nearly unchanged at multi-scan cyclic voltammogram. The mixture of CMS with $\mathrm{Hb}$ on the electrode can form a biocomposite with good stability, which is suitable for accelerating electron transfer from the electroactive center of $\mathrm{Hb}$ to the electrode. The cathodic (Epc) and the anodic (Epa) peak potential were found to be $-0.140 \mathrm{~V}$ and $-0.227 \mathrm{~V}$ with the $\Delta \mathrm{E}_{\mathrm{p}}$ as $87 \mathrm{mV}$. The formal peak potential $\left(\mathrm{E}^{0^{\prime}}\right)$ was calculated as $-0.184 \mathrm{~V}$ (vs. SCE). The ratio of the cathodic (Ipc) and the anodic (Ipa) peak current was found to be 1.06. To explore the best CV responses of $\mathrm{Hb}$ on CTS/CMS-Hb/CILE, the amount of CMS cast on the electrode was optimized in the control experiments with a concentration range of 0.05 to $5.0 \mathrm{mg} \cdot \mathrm{mL}^{-1}$. The highest redox currents appeared at $0.5 \mathrm{mg} \cdot \mathrm{mL}^{-1} \mathrm{CMS}$, which was used for electrode modification.

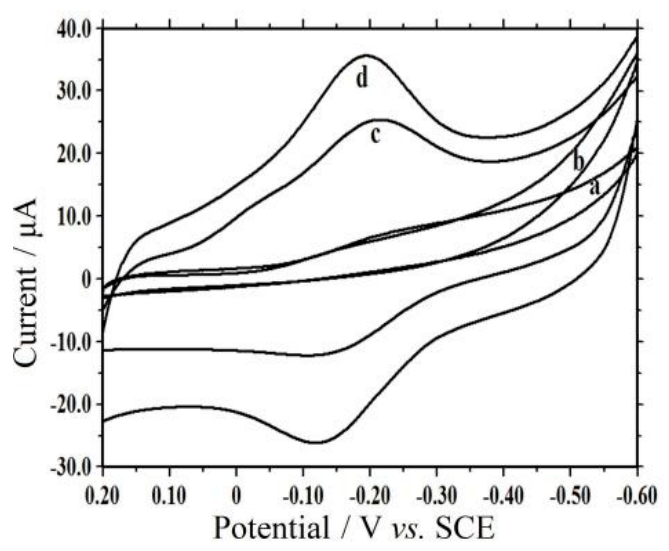

Figure 4. CV of (a) CILE; (b) CTS/CMS/CILE; (c) CTS/Hb/CILE and (d) CTS/CMS-Hb/CILE in pH 3.0 PBS, scan rate: $0.1 \mathrm{~V} \cdot \mathrm{s}^{-1}$.

\subsection{Electrochemical Investigation}

As shown in Figure $5 \mathrm{~A}$, the influence of scan rate $(v)$ on voltammetric responses of CTS/CMS-Hb/CILE was checked. A couple of redox peak appeared at different scan rates with the regression equations of peak currents and $v$ as $\operatorname{Ipc}(\mu \mathrm{A})=92.5 \cdot v\left(\mathrm{~V} \cdot \mathrm{s}^{-1}\right)+6.9$ $(\mathrm{n}=10, \gamma=0.999)$ and $\operatorname{Ipa}(\mu \mathrm{A})=-78.0 v \cdot\left(\mathrm{V} \cdot \mathrm{s}^{-1}\right)-10.0(\mathrm{n}=10, \gamma=0.999)$ (Figure 5B), indicating a surface-controlled thin-layer electrode behavior. The integration of the redox peak in cyclic voltammograms can count the surface coverage $\left(\Gamma^{*}\right)$ of electroactive $\mathrm{Hb}$ by the formula $\left(\Gamma^{*}=\mathrm{Q} / \mathrm{nAF}\right)$. By subtracting the background current, the peak currents of $\mathrm{Hb}$ were integrated with the $\Gamma^{*}$ value found to be $9.06 \times 10^{-10} \mathrm{~mol} \cdot \mathrm{cm}^{-2}$, which was larger than the theoretical monolayer coverage $\left(1.89 \times 10^{-11} \mathrm{~mol} \cdot \mathrm{cm}^{-2}\right)$ [27]. The fraction of electroactive $\mathrm{Hb}$ among the total $\mathrm{Hb}$ $\left(1.20 \times 10^{-8} \mathrm{~mol} \cdot \mathrm{cm}^{-2}\right)$ was calculated as $7.6 \%$. As shown in Figure $5 \mathrm{C}$, the increase in $v$ resulted in the change of the redox peak potentials and the relationships of Ep with $\ln v$ at high scan rate range were built. Two regression equations were got as $\operatorname{Epc}(\mathrm{V})=-0.03 \ln v-0.23(\mathrm{n}=7, \gamma=0.997)$ and 
$\mathrm{Epa}(\mathrm{V})=0.02 \ln v-0.10(\mathrm{n}=7, \gamma=0.993)$. Based on the Laviron's method [28], the kinetic of the redox reaction could be calculated with the electron transfer coefficient $(\alpha)$ and electron transfer rate constant $\left(k_{s}\right)$ as 0.444 and $0.946 \mathrm{~s}^{-1}$. The $k_{s}$ value was larger than those of Nafion/Hb-graphene oxide-IL/CILE $\left(0.92 \mathrm{~s}^{-1}\right)$ [29], GR/ $\mathrm{Fe}_{3} \mathrm{O}_{4} / \mathrm{Hb} / \mathrm{GCE}\left(0.30 \mathrm{~s}^{-1}\right)$ [30], Nafion/GR-TiO ${ }_{2}-\mathrm{Hb} / \mathrm{CILE}$ $\left(0.65 \mathrm{~s}^{-1}\right)$ [31] and $\mathrm{Hb}$-IL-MWCNT-CPE $\left(0.84 \mathrm{~s}^{-1}\right)$ [32], indicating a relatively high rate of electron transfer. Also the $k s$ value of CTS/Hb/CILE was calculated as $0.389 \mathrm{~s}^{-1}$ with the same method, which was less than that of CTS/CMS-Hb/CILE $\left(0.946 \mathrm{~s}^{-1}\right)$. Therefore the presence of CMS with high conductivity provides an enhanced electron transfer reaction for $\mathrm{Hb}$.
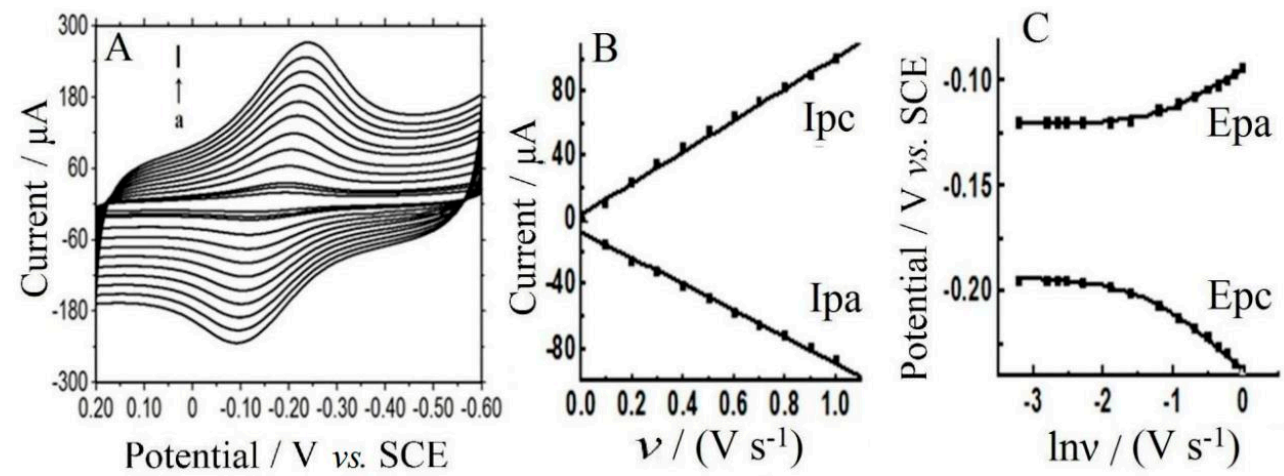

Figure 5. (A) Effect of scan rates $(v)$ (from a $\rightarrow 1$ as 50, 80, 100, 200, 300, 400, 500, 600, 700, 800, 900, $1000 \mathrm{mV} \cdot \mathrm{s}^{-1}$ ) on electrochemical responses of CTS/CMS-Hb/CILE in $\mathrm{pH} 3.0$ PBS; (B) Plot of the redox peak currents against $v$; (C) plot of the redox peak potentials against $\ln v$.

The influence of buffer $\mathrm{pH}$ on electrochemical behaviors of CTS/CMS- $\mathrm{Hb}$ /CILE was studied in different $\mathrm{PBS}$ and the results are displayed in Figure $6 \mathrm{~A}$. The linear equation between $E^{0^{\prime}}$ and $\mathrm{pH}$ was found to be $\mathrm{E}^{0^{\prime}}(\mathrm{mV})=-44.25 \cdot \mathrm{pH}-54.73(\gamma=0.998)$. The slope value $\left(-44.25 \mathrm{mV} \cdot \mathrm{pH}^{-1}\right)$ was smaller than the theoretical value $\left(-59.0 \mathrm{mV} \cdot \mathrm{pH}^{-1}\right)$ for a one-proton and one-electron transfer process [33,34]. At $\mathrm{pH} 3.0$ buffer solution, the largest redox peak currents appeared, and it was selected for the electrochemical experiments.
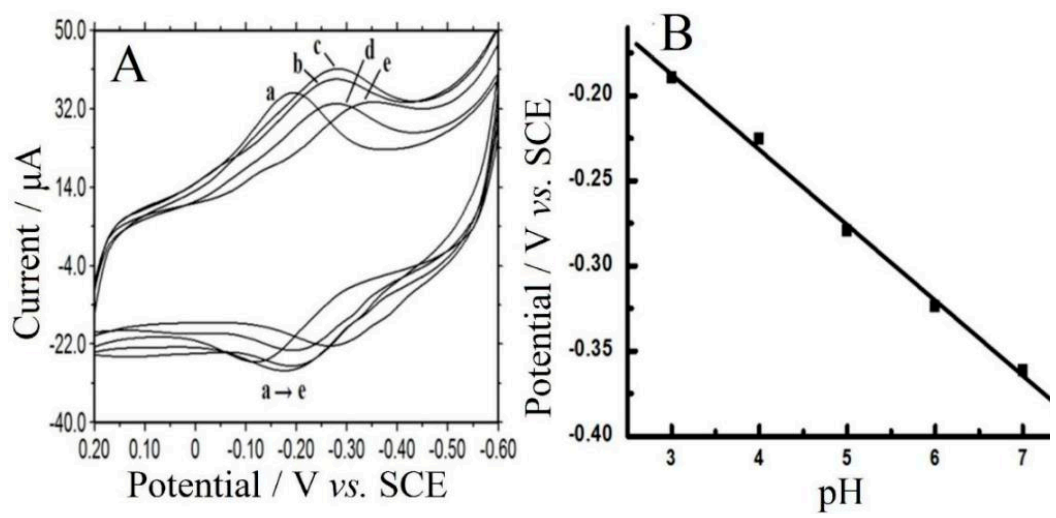

Figure 6. (A) CV of CTS/CMS-Hb/CILE in $0.1 \mathrm{~mol} \cdot \mathrm{L}^{-1}$ different $\mathrm{pH}$ PBS (from a $\rightarrow \mathrm{e}: 3.0,4.0,5.0,6.0$, 7.0), scan rate: $0.1 \mathrm{~V} \cdot \mathrm{s}^{-1} ;(\mathbf{B})$ the relationship of $\mathrm{E}^{0 \prime}$ with $\mathrm{pH}$.

\subsection{Electrocatalysis}

The redox-protein-based biosensor exhibits excellent electrocatalytic ability for TCA, which is an important analytical target in biochemistry and environmental chemistry. As shown in Figure 7, when various concentrations of TCA were analyzed by CTS/CMS-Hb/CILE, the reduction peak current increased at $-0.243 \mathrm{~V}$ without oxidation peak (curves a-h). With the further increase of the TCA 
concentration another reduction peak appeared at $-0.515 \mathrm{~V}$, indicated that di- and mono-chloroacetic acid might be dechlorinated by the formation of $\mathrm{Hb}[\mathrm{Hb} \mathrm{Fe}(\mathrm{I})]$ after TCA dechlorination with $\mathrm{Hb}$ $\mathrm{Fe}(\mathrm{II})$ [35]. On CTS/CMS/CILE direct electroreduction of TCA was studied with the potential negatively than $-0.8 \mathrm{~V}$ (curves $\mathrm{i}, \mathrm{j}$ ). Therefore the reduction potential of TCA was reduced due to the existence of $\mathrm{Hb}$. The reaction of electrocatalysis could be inferred from the following equations [35]:

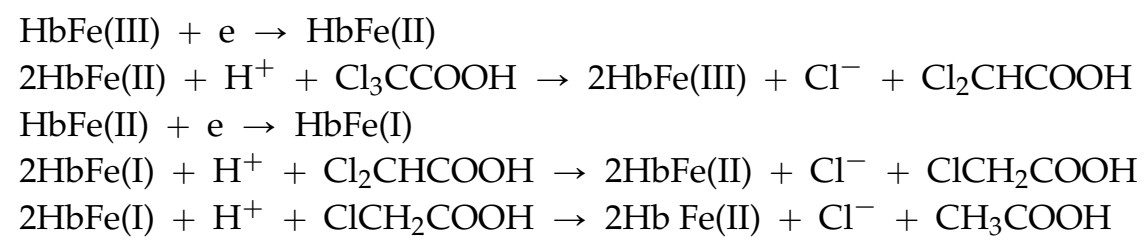

The catalytic cathodic peak current at $-0.243 \mathrm{~V}$ depended linearly on the TCA concentration with the equation of Iss $(\mu \mathrm{A})=3.04 \mathrm{C}\left(\mathrm{mmol} \cdot \mathrm{L}^{-1}\right)-4.89(\mathrm{n}=13, \gamma=0.999)$. The linear range and the detection limit were obtained as $2.0 \sim 70.0 \mathrm{mmol} \cdot \mathrm{L}^{-1}$ and $0.30 \mathrm{mmol} \cdot \mathrm{L}^{-1}(3 \sigma)$, respectively. The cathodic peak current reached a stable value when the TCA concentration exceeded $70.0 \mathrm{mmol} \cdot \mathrm{L}^{-1}$, indicating a typical Michaelis-Menten kinetic process. The Lineweaver-Burk equation of $1 / \mathrm{I}_{\mathrm{ss}}=\left(1 / \mathrm{I}_{\max }\right)\left(1+K_{M}^{a p p} / C\right)$ [36] was used to calculate the apparent Michaelis-Menten constant $\left(K_{M}{ }^{a p p}\right)$ at a value of $1.60 \mathrm{mmol} \cdot \mathrm{L}^{-1}$, which was smaller than those of published values [27,37-39]. The low KMapp value indicated that $\mathrm{Hb}$ entrapped on the electrode retained its bioactivity and had a much higher biological affinity to TCA.

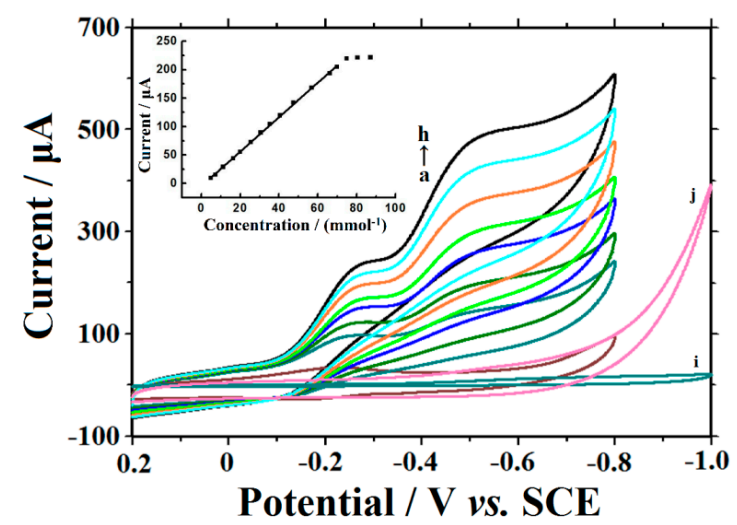

Figure 7. CV of CTS/CMS-Hb/CILE with 0 , 15.0, 25.0, 35.0, 45.0, 55.0, 65.0, $70.0 \mathrm{mmol} \cdot \mathrm{L}^{-1}$ TCA (curves $\mathrm{a} \rightarrow \mathrm{h}$ ) and of CTS/CMS/CILE with of $0,80.0 \mathrm{mmol} \cdot \mathrm{L}^{-1} \mathrm{TCA}$ (curves $\mathrm{i}$ and $\mathrm{j}$ ), scan rate: $0.1 \mathrm{~V} \cdot \mathrm{s}^{-1}$ (Inset was the linearity of catalytic reduction currents and TCA concentration).

\subsection{Analytical Application}

To verify its application, CTS/CMS-Hb/CILE was used for determining of TCA in lab water with the standard addition method. As shown in Table 1, no TCA were found in the water specimens and the recovery was in the range of $97.00 \%-104.00 \%$. Therefore this $\mathrm{Hb}$-modified electrode could be used for water specimen detection.

Table 1. Detection results of TCA in the lab water specimen $(n=3)$.

\begin{tabular}{cccccc}
\hline Specimen & $\begin{array}{c}\text { Found } \\
\left(\mathbf{m m o l} \cdot \mathbf{L}^{-1} \mathbf{)}\right.\end{array}$ & $\begin{array}{c}\text { Added } \\
\left.\mathbf{( m m o l} \cdot \mathbf{L}^{-1}\right)\end{array}$ & $\begin{array}{c}\text { Total } \\
\left(\mathbf{m m o l} \cdot \mathbf{L}^{-1} \mathbf{)}\right.\end{array}$ & $\begin{array}{c}\text { Recovery } \\
\mathbf{( \% )}\end{array}$ & $\begin{array}{c}\text { RSD } \\
\mathbf{( \% )}\end{array}$ \\
\hline \multirow{3}{*}{ water } & & 2.00 & 2.08 & 104.00 & 3.06 \\
& 0 & 4.00 & 3.88 & 97.00 & 3.10 \\
& & 6.00 & 6.12 & 102.00 & 2.98 \\
\hline
\end{tabular}




\subsection{Stability and Reproducibility}

The reproducibility was studied by applying six $\mathrm{Hb}$-modified electrodes to the determination of $10.0 \mathrm{mmol} \cdot \mathrm{L}^{-1} \mathrm{TCA}$ independently. An acceptable relative standard deviation (RSD) of $2.15 \%$ was determined. CTS/CMS-Hb/CILE was put into a $4{ }^{\circ} \mathrm{C}$ refrigerator for a certain period to check the storing stability. Every 5 days, the peak response of CTS/CMS-Hb/CILE to $10.0 \mathrm{mmol} \cdot \mathrm{L}^{-1} \mathrm{TCA}$ was tested, which decreased by $3.1 \%$ after 10 days and $7.5 \%$ for 25 -days storage, proving the relative good stability of CTS/CMS-Hb/CILE.

\section{Conclusions}

CMS was prepared using a hydrothermal method and direct electrochemistry of $\mathrm{Hb}$ was carried out on CMS-modified CILE. A couple of well-defined redox peaks could be seen on $\mathrm{CTS} / \mathrm{CMS}-\mathrm{Hb} / \mathrm{CILE}$, indicating the acceleration of direct electron transfer of $\mathrm{Hb}$ due to high conductivity, large surface area and good biocompatibility of CMS. The immobilized Hb molecules kept their original structure and exerted good electrocatalytic ability for the reduction of TCA. As compared with other types of redox-protein-modified electrodes for TCA detection [29,31,37-39], this $\mathrm{Hb}$-based electrode exhibited advantages such as favorable sensitivity, linear range, detection limit, stability and reproducibility. Hence, CMS has potential for the construction of third-generation redox-protein-based bioelectrochemical sensors.

Acknowledgments: We acknowledge the financial support of the National Natural Science Foundation of China (Nos. 21365010 and 51363008), the Nature Science Foundation of Hainan Province (20152016), the International Science and Technology Cooperation Project of Hainan Province (KJHZ2015-13), the Marine Science and Technology Program of Hainan Province (2015XH06) and Graduate Student Innovation Research Projects of Hainan Normal University (Hsyx2015-47).

Author Contributions: All authors contributed extensively to the work in this paper. Wen-Cheng Wang synthesized the sensing material, Li-Jun Yan preformed the electrocatalysis, Fan Shi prepared the modified electrode, Xue-liang Niu conducted the sensor analysis, Guo-Lei Huang characterized the carbon microsphere, Cai-juan Zheng conducted the characterization of protein, and Wei Sun investigated the electrochemical performances.

Conflicts of Interest: The authors declare no conflict of interest.

\section{Abbreviations}

The abbreviations involved in the paper.

\begin{tabular}{llll}
\hline Sigillum & Full Caption & Sigillum & Full Caption \\
\hline BPPF $_{6}$ & 1-butylpyridinium hexafluorophosphate & HOAC & acetic acid \\
CILE & carbon ionic liquid electrode & IL & ionic liquid \\
CPE & carbon paste electrode & Ipa & anodic peak current \\
CMS & carbon microsphere & Ipc & cathodic peak current \\
CTS & chitosan & $K_{M} a p p$ & apparent michaelis-menten constant \\
CV & cyclic voltammograms & MWCNT & multi-walled carbon nanotube \\
EIS & electrochemical impedance spectroscopy & PBS & phosphate buffer solutions \\
$\mathrm{E}^{0^{\prime}}$ & formal peak potential & Ret & the electron transfer resistance \\
Epa & anodic peak potential & RSD & the relative standard deviation \\
Epc & cathodic peak potential & SEM & scanning electron microscopy \\
GOD & glucose oxidase & TCA & trichloroacetic acid \\
GR & graphene & TEM & transmission electron microscopy \\
GCE & glass carbon electrode & XRD & X-ray diffraction \\
Hb & hemoglobin & $\Gamma^{*}$ & surface coverage \\
\hline
\end{tabular}




\section{References}

1. Armstrong, F.A.; Hill, H.A.O.; Walton, N.J. Direct electrochemistry of redox proteins. Acc. Chem. Res. 1988, 21, 407-413. [CrossRef]

2. Ramanavicius, A.; Ramanaviciene, A. Hemoproteins in design of biofuel cells. Fuel Cells 2009, 1, 25-36. [CrossRef]

3. Armstrong, F.A.; Wilson, G.S. Recent developments in faradaic bioelectrochemistry. Electrochim. Acta 2000, 45, 2623-2645. [CrossRef]

4. Prakash, P.A.; Yogeswaran, U.; Chen, S.M. A review on direct electrochemistry of catalase for electrochemical sensors. Sensors 2009, 9, 1821-1844. [CrossRef] [PubMed]

5. Blanford, C.F. The birth of protein electrochemistry. Chem. Commun. 2013, 49, 11130-11132. [CrossRef] [PubMed]

6. Mani, V.; Devadas, B.; Chen, S.M.; Li, Y. Immobilization of enzymes and redox proteins and their electrochemical biosensor applications. ECS Trans. 2013, 50, 35-41. [CrossRef]

7. Sun, W.; Guo, C.X.; Zhu, Z.H.; Li, C.M. Ionic liquid/mesoporous carbon/protein composite microelectrode and its biosensing application. Electrochem. Commun. 2009, 11, 2105-2108. [CrossRef]

8. Wang, J.; Li, M.; Shi, Z.; Li, N.; Gu, Z. Direct electrochemistry of cytochrome c at a glassy carbon electrode modified with single-wall carbon nanotubes. Anal. Chem. 2002, 74, 1993-1997. [CrossRef] [PubMed]

9. Li, M.G.; Xu, S.D.; Tang, M.; Liu, L.; Gao, F.; Wang, Y.L. Direct electrochemistry of horseradish peroxidase on graphene-modified electrode for electrocatalytic reduction towards $\mathrm{H}_{2} \mathrm{O}_{2}$. Electrochim. Acta 2011, 56, 1144-1149. [CrossRef]

10. Kang, X.H.; Wang, J.; Wu, H.; Aksay, I.A.; Liu, J.; Lin, Y.H. Glucose oxidase-graphene-chitosan modified electrode for direct electrochemistry and glucose sensing. Biosens. Bioelectron. 2009, 25, 901-905. [CrossRef] [PubMed]

11. Shin, Y.S.; Wang, L.Q.; Bae, I.T.; Arey, B.W.; Exarhos, G.J. Hydrothermal syntheses of colloidal carbon spheres from cyclodextrins. J. Phys. Chem. C 2008, 112, 14236-14240. [CrossRef]

12. Sun, X.M.; Li, Y.D. Colloidal carbon spheres and their core/shell structures with noble-metal nanoparticles. Angew. Chem. Int. Ed. 2004, 43, 597-601. [CrossRef] [PubMed]

13. Chen, J.X.; Xia, N.N.; Zhou, T.X.; Tan, S.X.; Jiang, F.P.; Yuan, D.S. Mesoporous carbon spheres: Synthesis, characterization and supercapacitance. Int. J. Electrochem. Sci. 2009, 4, 1063-1073.

14. Jin, Y.Z.; Gao, C.; Hsu, W.K.; Zhu, Y.Q.; Huczko, A.; Bystrzejewski, M.; Roe, M.; Lee, C.Y.; Acquah, S.; Kroto, H.; et al. Large-scale synthesis and characterization of carbon spheres prepared by direct pyrolysis of hydrocarbons. Carbon 2005, 43, 1944-1953. [CrossRef]

15. Auer, E.; Freund, A.; Pietsch, J.; Tacke, T. Carbons as supports for industrial precious metal catalysts. Appl. Catal. A 1998, 173, 259-271. [CrossRef]

16. Wang, Y.; Su, F.; Wood, C.D.; Lee, J.Y.; Zhao, X.S. Preparation and characterization of carbon nanospheres as anode materials in lithium-ion secondary batteries. Ind. Eng. Chem. Res. 2008, 47, 2294-2300. [CrossRef]

17. Yan, X.B.; Xu, T.; Xu, S.; Chen, G.; Liu, H.W.; Yang, S.R. Fabrication of carbon spheres on a C: H films by heat-treatment of a polymer precursor. Carbon 2004, 42, 2769-2771. [CrossRef]

18. Shiddiky, M.J.A.; Torriero, A.A.J. Application of ionic liquids in electrochemical sensing systems. Biosens. Bioelectron. 2011, 26, 1775-1787. [CrossRef] [PubMed]

19. Sun, W.; Gao, R.F.; Jiao, K. Research and application of ionic liquids in analytical chemistry. Chin. J. Anal. Chem. 2007, 35, 1813-1819.

20. Sheng, M.L.; Gao, Y.; Sun, J.Y.; Gao, F. Carbon nanodots-chitosan composite film: a platform for protein immobilization, direct electrochemistry and bioelectrocatalysis. Biosens. Bioelectron. 2014, 58, 351-358. [CrossRef] [PubMed]

21. Sun, W.; Yang, M.X.; Jiao, K. Electrocatalytic oxidation of dopamine at an ionic liquid modified carbon paste electrode and its analytical application. Anal. Bioanal. Chem. 2007, 389, 1283-1291. [CrossRef] [PubMed]

22. Xu, X.; Shi, B.X.; Zheng, W.; Xia, W.; Guang, H. Photo-responsive behaviors and structural evolution of carbon-nanotube-supported energetic materials under a photoflash. Mater. Lett. 2012, 88, 27-29. [CrossRef]

23. Byler, D.M.; Susi, H. Examination of the secondary structure of proteins by deconvolved FTIR spectra. Biopolymers 1986, 25, 469-487. [CrossRef] [PubMed] 
24. Kauppinen, J.K.; Moffat, D.J.; Mantsch, H.H.; Cameron, D.G. Fourier self-deconvolution: A method for resolving intrinsically overlapped ban. Appl. Spectrosc. 1981, 35, 271-276. [CrossRef]

25. Rusling, J.F.; Nassar, A.E.F. Enhanced electron transfer for myoglobin in surfactant films on electrodes. J. Am. Chem. Soc. 1993, 115, 11891-11897. [CrossRef]

26. Orazem, M.E.; Tribollet, B. An integrated approach to electrochemical impedance spectroscopy. Electrochim. Acta 2008, 53, 7360-7366. [CrossRef]

27. Wang, S.F.; Chen, T.; Zhang, Z.L.; Shen, X.C.; Lu, Z.X.; Pang, D.W.; Wong, K.Y. Direct electrochemistry and electrocatalysis of heme proteins entrapped in agarose hydrogel films in room-temperature ionic liquids. Langmuir 2005, 21, 9260-9266. [CrossRef] [PubMed]

28. Laviron, E. General expression of the linear potential sweep voltammogram in the case of diffusionless electrochemical systems. J. Electroanal. Chem. 1979, 101, 19-28. [CrossRef]

29. Sun, W.; Gong, S.X.; Shi, F.; Cao, L.L.; Ling, L.Y.; Zheng, W.Z.; Wang, W.C. Direct electrochemistry and electrocatalysis of hemoglobin in graphene oxide and ionic liquid composite film. Mater. Sci. Eng. C 2014, 40, 235-241. [CrossRef] [PubMed]

30. Wang, Y.Q.; Zhang, H.J.; Yao, D.; Pu, J.J.; Zhang, Y.; Gao, X.R.; Sun, Y.M. Direct electrochemistry of hemoglobin on graphene $/ \mathrm{Fe}_{3} \mathrm{O}_{4}$ nanocomposite-modified glass carbon electrode and its sensitive detection for hydrogen peroxide. J. Solid State Electrochem. 2013, 17, 881-887. [CrossRef]

31. Sun, W.; Guo, Y.Q.; Ju, X.M.; Zhang, Y.Y.; Wang, X.Z.; Sun, Z.F. Direct electrochemistry of hemoglobin on graphene and titanium dioxide nanorods composite modified electrode and its electrocatalysis. Biosens. Bioelectron. 2013, 42, 207-213. [CrossRef] [PubMed]

32. Wei, W.; Jin, H.H.; Zhao, G.C. A reagentless nitrite biosensor based on direct electron transfer of hemoglobin on a room temperature ionic liquid/carbon nanotube-modified electrode. Microchim. Acta 2009, 164, 167-171. [CrossRef]

33. Yamazaki, I.; Araiso, T.; Hayashi, Y.; Yamada, H.; Makino, R. Analysis of acid-base properties of peroxidase and myoglobin. Adv. Biophys. 1978, 11, 249-281. [PubMed]

34. Liu, H.H.; Tian, Z.Q.; Lu, Z.X.; Zhang, Z.L.; Zhang, M.; Pang, D.W. Direct electrochemistry and electrocatalysis of heme-proteins entrapped in agarose hydrogel films. Biosens. Bioelectron. 2004, 20, 294-304. [CrossRef] [PubMed]

35. Fan, C.H.; Zhuang, Y.; Li, G.X.; Zhu, J.Q.; Zhu, D.X. Direct electrochemistry and enhanced catalytic activity for hemoglobin in a sodium montmorillonite film. Electroanal 2000, 12, 1156-1158. [CrossRef]

36. Kamin, R.A.; Wilson, G.S. Rotating ring-disk enzyme electrode for biocatalysis kinetic studies and characterization of the immobilized enzyme layer. Anal. Chem. 1980, 52, 1198-1205. [CrossRef]

37. Sun, W.; Li, X.Q.; Wang, Y.; Zhao, R.J.; Jiao, K. Electrochemistry and electrocatalysis of hemoglobin on multi-walled carbon nanotubes modified carbon ionic liquid electrode with hydrophilic EMIMBF4 as modifier. Electrochim. Acta 2009, 54, 4141-4148. [CrossRef]

38. Zhang, Z.Q.; Wu, J.; Sun, W.; Jiao, K. Direct electrochemistry of hemoglobin and its electrocatalysis based on a carbon nanotube paste electrode. J. Chin. Chem. Soc. 2009, 56, 561-567.

39. Sun, W.; Guo, Y.Q.; Lu, Y.P.; Hu, A.H.; Shi, F.; Li, T.T.; Sun, Z.F. Electrochemical biosensor based on graphene, $\mathrm{Mg}_{2} \mathrm{Al}$ layered double hydroxide and hemoglobin composite. Electrochim. Acta 2013, 91, 130-136. [CrossRef]

(C) 2015 by the authors; licensee MDPI, Basel, Switzerland. This article is an open access article distributed under the terms and conditions of the Creative Commons by Attribution (CC-BY) license (http:/ / creativecommons.org/licenses/by/4.0/). 